\title{
The Potential of Topical and Injectable Growth Factors and Cytokines for Skin Rejuvenation
}

\author{
Sabrina Fabi, MD, FAAD ${ }^{1,2}$ Hema Sundaram, MD, FAAD ${ }^{3}$ \\ ${ }^{1}$ Goldman, Butterwick, Fitzpatrick, Groff \& Fabi, Cosmetic Laser \\ Dermatology, San Diego, California \\ 2 Department of Dermatology, University of California, San Diego, \\ California \\ ${ }^{3}$ Sundaram Dermatology, Cosmetic \& Laser Surgery, Rockville, \\ Maryland
}

Facial Plast Surg 2014;30:157-171

\begin{abstract}
Address for correspondence Hema Sundaram, MD, Sundaram Dermatology, Cosmetic \& Laser Surgery, 11119 Rockville Pike Suite 205, Rockville, MD 20852 (e-mail: hemasundaram@gmail.com).
\end{abstract}

\section{Abstract}

\section{Keywords}

- growth factors

- cosmeceuticals

- platelet-rich plasma

- skin aging

- skin rejuvenation

- cytokines

- platelet-rich fibrin matrix

- transforming growth factor- $\beta$

- platelet-derived growth factor

- vascular endothelial growth factor
Growth factors and cytokines (referred to collectively hereafter as GFs) control cell growth, proliferation, and differentiation via a network of inter and intracellular signaling pathways. There are striking parallels between the pathways involved in skin wound healing and those implicated in photoaging of the skin. In recent years, topical and injectable GFs have emerged as an intriguing therapeutic modality that can be harnessed for aesthetic and medical purposes. This article provides a review of available evidence for the role in skin regeneration of topical GFs, and of injectable GFs contained in autologous platelet-rich plasma (PRP). It presents data from recent studies of GFs, offers a discussion of their potential to serve as antiaging actives, and includes safety considerations. As studies of injectable GFs typically assume preexisting familiarity with PRP protocols and the theory behind them, explanatory notes are provided. An assessment is provided of the evidence gaps that exist currently between experimental observations regarding GFs and their proven clinical benefits. Data of evidence levels II and III support the use for skin rejuvenation of topical GFs derived from sources including secretions or lysate of human dermal fibroblasts, and secretions of the snail Cryptomphalus aspersa. GFs with associated stem cell proteins, secreted by human dermal fibroblasts under hypoxic stress, can accelerate skin healing after laser resurfacing. In vitro and animal studies, small case series of PRP-treated patients and one prospective clinical study of its variant, platelet-rich fibrin matrix (PRFM), suggest the value of injectable GFs for skin rejuvenation. However, data of higher power are required to expand this proof of concept into an evidence-based paradigm. The clinical applications of topical and injectable GFs are promising, and remain to be fully defined. With continued study, data of higher evidence level can be accrued and formulations can be developed that offer optimal clinical efficacy, safety, tolerability, and stability. Better understanding of the mechanism of action of GFs can potentially advance our general understanding of dermal signaling pathways, and hence of hyaluronic acid and other alloplastic fillers; and allow the development of protocols for synergistic combination of GFs with other skin rejuvenation modalities.
Issue Theme 11th International Symposium of Facial Plastic Surgery; Guest Editors, Jonathan M. Sykes, MD, FACS, and Anthony P. Sclafani, MD, FACS
Copyright @ 2014 by Thieme Medical Publishers, Inc., 333 Seventh Avenue, New York, NY 10001, USA.

Tel: +1(212) 584-4662.
DOI http://dx.doi.org/ 10.1055/s-0034-1372423. ISSN 0736-6825. 
In recent years, topical and injectable growth factors and cytokines have emerged as intriguing therapeutic modalities, with burgeoning interest in their potential to serve as actives for skin rejuvenation. Growth factors and cytokines (hereafter referred to collectively as GFs) may be applied topically in cosmeceutical formulations, or injected in autologous platelet-rich plasma (PRP). Understanding of the scientific rationale for these treatments requires insight into the pathophysiology of skin aging, and how this may be addressed at a cellular level.

The skin's mechanical, protective, and restorative properties decline with age. Daily exposure to extrinsic, environmental stressors, including ultraviolet (UV) light and cigarette smoke, increases oxidative stress. This results in tissue damage, due to antioxidant depletion coupled with increased production of reactive oxygen species (ROS-also known as free radicals). Multiple biochemical pathways that are triggered by ROS overload result in suppression of transforming growth factor- $\beta$ receptor II (TGF- $\beta$-R2), ${ }^{1}$ overexpression of matrix metalloproteinases (MMPs) which are collagenases, ${ }^{2}$ and increased inflammation through the nuclear factor kappa $\beta$ pathway. ${ }^{3}$ UV radiation also causes direct damage to the skin's structural proteins. ${ }^{3}$

These extrinsic factors augment the skin's intrinsic deterioration, which is related to a progressive, age-related decline in antioxidant capacity coupled with increased production of ROS from oxidative metabolism in cells of the skin. ${ }^{4,5}$ Intrinsic deterioration contributes to ROS overload and the biochemical effects described earlier. Analysis of aging cells reveals progressive telomere shortening, which is also related to tissue damage.

-Fig. 1 shows a summary of major pathways involved in skin aging.

Extrinsic and intrinsic aging of the skin results in breakdown of the collagen and elastin network in the dermis. This manifests clinically as xerosis, loss of elasticity, atrophy, dyschromia, and rhytides. The quest for safe, noninvasive treatments to reverse or retard these changes remains challenging.

Research into acute and chronic wound healing has provided insight into the pathophysiology of photoaging (dermatoheliosis). There are several parallels between pathways involved in wound healing and those necessary for regeneration of aging skin. Some of the biochemical changes that would be needed to reverse the effects of intrinsic and extrinsic skin aging are similar to the changes that occur during wound formation and its aftermath. ${ }^{4,5}$ Therefore, an understanding of the wound healing process may enhance understanding of skin aging and the interventions that can be attempted to address it. Our focus in this article is on the primary role that can be played in these interventions by topical and injectable GFs.

GFs comprise a large group of regulatory proteins that attach to cell surface receptors and serve as chemical messengers. Via this interaction, they mediate inter and intracellular signaling pathways that control cell growth, proliferation, and differentiation. Unlike hormones, the activity of GFs is confined to the vicinity of their sites of production. In the skin, GFs are synthesized by fibroblasts, keratinocytes, platelets, lymphocytes, and mast cells. ${ }^{4}$ Specific GFs regulate vital cellular activities, including mitogenesis, angiogenesis, chemotaxis, formation of the extracellular matrix (ECM) and control of other GFs. ${ }^{6}$ - Tables 1 and 2 show some mechanisms of action that have been identified for key and supplemental GFs. ${ }^{7,8}$

When the skin is wounded, GFs accumulate at the site of injury and interact synergistically to initiate and coordinate wound healing. They can reverse the effects of collagenases, increase collagen levels, and decrease tissue inflammation. Clinical studies have demonstrated that topical application of human or animal-derived GFs or injection of autologous GFs may also increase dermal collagen synthesis, and that this is

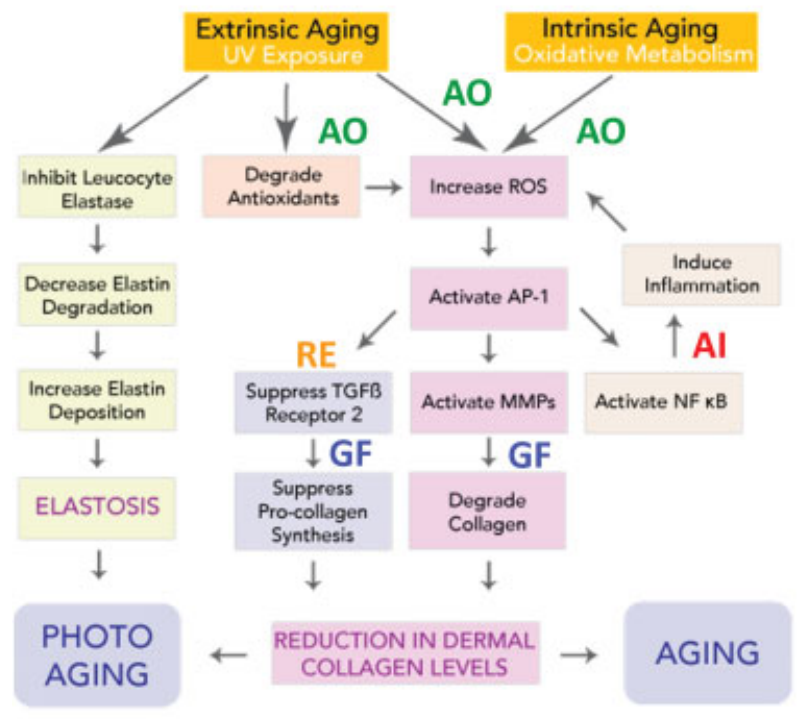

\section{ROS - Reactive Oxygen Species}

AP-1 - Activator Protein 1

TGF - Transforming Growth Factor

MMP - Matrix Metalloproteinase

NFkB - Nuclear Factor Kappa-B

\section{AO Antioxidants}

Al Anti-inflammatory

RE Retinoids

GF Growth Factors and Mimicking Peptides

Fig. 1 Simplified overview of extrinsic and intrinsic biochemical pathways of skin aging. Courtesy of SkinMedica, Inc., Carlsbad, CA. Reproduced with permission from Fabi and Sundaram. $1,2,4,5,7$ 
Table 1 Key growth factors and cytokines 8,9

\begin{tabular}{|l|l|l|}
\hline Growth factor & Phase in wound healing & Mechanism of action \\
\hline $\begin{array}{l}\text { Platelet-derived growth factor } \\
\text { (PDGF)-PDGF AA, PDGF BB }\end{array}$ & $\begin{array}{l}\text { Inflammatory and } \\
\text { proliferative }\end{array}$ & $\begin{array}{l}\text { Mitogenic for fibroblasts and smooth muscle cells } \\
\text { Chemotactic for mesenchymal stem cells, fibro- } \\
\text { blasts, smooth muscle cells, macrophages, mono- } \\
\text { cytes, neutrophils, and thrombin-activated platelets } \\
\text { Fibroblast proliferation and migration } \\
\text { Believed to regulate cell growth and division in } \\
\text { wound healing }\end{array}$ \\
\hline $\begin{array}{l}\text { Vascular endothelial growth } \\
\text { factor }\end{array}$ & $\begin{array}{l}\text { Inflammatory and } \\
\text { proliferative }\end{array}$ & $\begin{array}{l}\text { Mediates extracellular matrix synthesis and } \\
\text { deposition } \\
\text { Promotes angiogenesis } \\
\text { Chemotactic for endothelial cells } \\
\text { Mitogenic for endothelial cells and keratinocytes } \\
\text { Believed to increase blood vessel permeability to } \\
\text { improve tissue nutrition }\end{array}$ \\
\hline $\begin{array}{l}\text { Transforming growth factor } \beta \\
\text { (TGF- } \beta \text { )-TGF- } \beta 1, \text { TGF- } \beta 2, \text { TGF- } \\
\beta 3\end{array}$ & Inflammatory and proliferative & $\begin{array}{l}\text { Mediates extracellular matrix formation } \\
\text { Keratinocyte migration in reepithelization } \\
\text { Stimulates angiogenesis } \\
\text { Stimulates type I and type III collagen production } \\
\text { Stimulates fibroblasts and mesenchymal stem cells } \\
\text { proliferation }\end{array}$ \\
\hline $\begin{array}{l}\text { Tissue inhibitor of metallopro- } \\
\text { teinases (TIMP)-TIMP1, TIMP2 }\end{array}$ & Proliferative & $\begin{array}{l}\text { Regulates enzyme activity preventing breakdown of } \\
\text { collagen and hyaluronic acid }\end{array}$ \\
\hline
\end{tabular}

Source: Adapted from Sundaram et al. ${ }^{8}$

associated with reduced signs of skin aging such as fine lines and wrinkles. It is postulated that GFs can act synergistically to produce the desired effects. As our understanding of their mechanisms of action and efficacy increases, so will our ability to fully apply their benefits in the clinical setting.

\section{Pathophysiology of Skin Aging}

Intrinsic and extrinsic skin aging are cumulative processes that result in reduced dermal collagen levels and the devel- opment of elastosis. Histological evaluation reveals that sundamaged skin has a flattened dermoepidermal interface with loss of dermal papillae, decreased dermal thickness and vascularity, decreased fibroblast activity, and haphazardly arranged, fragmented elastin fibers. ${ }^{10}$ Decreased total elastin content and reduced ability to synthesize type I procollagen have been observed in physiologically older, sun-damaged skin, in comparison to young, undamaged skin. ${ }^{11,12}$ Comparative study of photodamaged versus sun-protected skin shows a statistically significant decrease (20\%) in total

Table 2 Supplemental growth factors ${ }^{8,9}$

\begin{tabular}{|c|c|c|}
\hline Growth factor & Phase in wound healing & Mechanism of action \\
\hline $\begin{array}{l}\text { Fibroblast growth factors (FGF)- } \\
\text { FGF-2, FGF-4, KGF (FGF-7), FBF-9 }\end{array}$ & Proliferative & $\begin{array}{l}\text { Stimulates and mediates angiogenesis } \\
\text { Endothelial and fibroblast proliferation and migration } \\
\text { Fibronectin synthesis and secretion } \\
\text { Believed to promote skin cell growth and tissue repair }\end{array}$ \\
\hline Hepatocyte growth factor & Inflammatory & $\begin{array}{l}\text { Mediates extracellular matrix formation } \\
\text { Believed to promote three dimensional tissue growth }\end{array}$ \\
\hline $\begin{array}{l}\text { Insulin-like growth factor (IGF)- } \\
\text { IGF1, IGFBP1, IGFBP2, IGFBP3, } \\
\text { IGFBP6 }\end{array}$ & Proliferative & Believed to promote cell growth and multiplication \\
\hline Placenta growth factor & Proliferative & Believed to promote endothelial cell growth \\
\hline Bone morphogenetic protein & Proliferative & $\begin{array}{l}\text { Believed to promote development of nerve } \\
\text { cells in developing tissue }\end{array}$ \\
\hline $\begin{array}{l}\text { Interleukins-15 different interleu- } \\
\text { kins, including IL-10 and IL-13 }\end{array}$ & $\begin{array}{l}\text { Inflammatory and } \\
\text { Proliferative }\end{array}$ & $\begin{array}{l}\text { Believed to play a critical role in inflammation } \\
\text { and wound healing }\end{array}$ \\
\hline Colony stimulating factors & Inflammatory and Proliferative & Believed to induce secretion of other cytokines \\
\hline
\end{tabular}

Source: Adapted from Sundaram et al. ${ }^{8}$ 


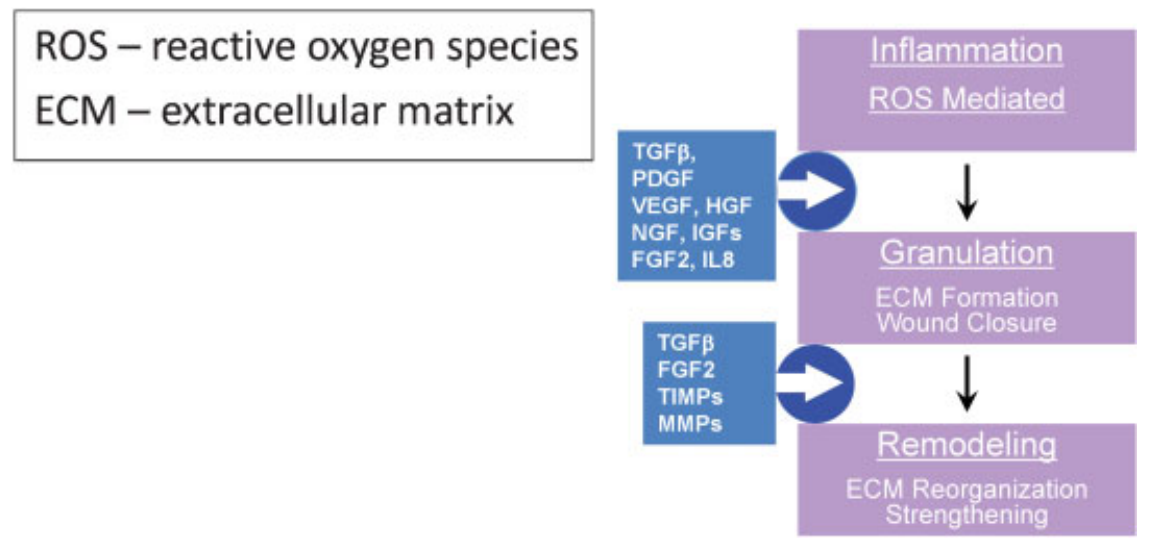

Fig. 2 Key growth factors and cytokines which are active during the three main stages of wound healing. Successful wound healing involves multiple GFs, including PDGF, VEGF, TGF- $\beta$, EGF, G-CSF, KGF, IL-6, IL-8, and HGF. Reproduced with permission from Fabi and Sundaram. ${ }^{7}$ ECM, extracellular matrix; EGF, epidermal growth factor; G-CSF, granulocyte colony-stimulating growth factor; GF, growth factor; HGF, hepatocyte growth factor; IL-6, interleukin 6; IL-8, interleukin 8; KGF, keratinocyte growth factor; PDGF, platelet-derived growth factor; ROS, reactive oxygen species; TGF, transforming growth factor; VEGF, vascular endothelial growth factor.

collagen. ${ }^{12}$ As both sun-protected and photodamaged skin show a reduction in mean epidermal thickness with age, this may be inferred to be a manifestation of intrinsic aging. ${ }^{12}$ The production and levels of GFs in the skin are also diminished with age. $^{13}$

\section{Comparison of Skin Rejuvenation with Wound Healing}

The healing of skin wounds is precisely regulated by complex interactions between GFs that result in signaling cascades. - Fig. 2 shows key GFs that are active during the three main stages of wound healing-initial, ROS-mediated inflammation; subsequent wound granulation; and, finally, wound remodeling. Successful wound healing entails a balance between development of inflammation and its resolution. This involves multiple GFs, including platelet-derived growth factor (PDGF), vascular endothelial growth factor (VEGF), transforming growth factor- $\beta$ (TGF- $\beta$ ), epidermal growth factor (EGF), granulocyte colony-stimulating growth factor (G-CSF), keratinocyte growth factor (KGF), interleukin 6 (IL-6), interleukin 8 (IL-8), and hepatocyte growth factor (HGF). ${ }^{14,15}$ GFs relevant to wound healing induce dermal remodeling by stimulating synthesis of new collagen, elastin, and glycosaminoglycans, and by mediating angiogenesis (-Tables 1 and 2).

There are striking similarities between these events and those that could effectively address the effects of intrinsic and extrinsic skin aging. GF levels in the body peak in youth and decline thereafter. It has been hypothesized that skin aging is analogous to a wound that is sufficiently extensive to overwhelm the skin's inherent repair mechanisms, which become attenuated with age. ${ }^{8}$ The aim of administering topical or injectable GFs is to replenish the skin's own depleted levels and to upregulate the activity of cells responsible for dermal remodeling, thereby slowing or even reversing the manifestations of skin aging. This rationale can be extended to iatrogenic skin wounding, such as during laser and other skin rejuvenation procedures-the hypothesis being that topical and injectable GFs may also facilitate healing in this situation, and perhaps even enhance the results.

Once skin injury has occurred, the wound healing response is initiated to promote new cell growth and to decrease wound contraction and scarring. Wound healing is commonly divided into four phases-hemostasis, inflammation, proliferation, and remodeling. Each phase is controlled by GFs, as is transition from one phase to the next. The parallel between skin wounding and skin aging is heightened by the fact that the initial inflammation seen in wounded skin is ROS-mediated, just like the changes seen in aging skin. It is of note that the ROS-mediated inflammation associated with wound formation or acute, extrinsic photodamage is not seen with intrinsic aging. The proliferative phase of wound healing, known as the granulation phase, is marked by angiogenesis, fibroplasia, and ECM deposition, all leading to reepithelialization. The remodeling phase, also known as the maturation phase, is the final stage of wound healing, after granulation and wound reepithelialization or desquamation of sunburned skin. During this stage of wound repair, ECM is deposited and remodeled. Type III collagen and initial elastin structures, which are produced during early wound healing, have been described as being less structured and of lower tensile strength. They are replaced by stronger type I collagen and structured elastin fibers. This remodeling phase can last for several months, and restores dermal strength and resilience.

\section{Topical and Injectable Growth Factors and Cytokines}

\section{Potential Mechanisms of Action}

Topical and injectable GFs have the potential to modulate complex cellular communication that ultimately results in upregulation of collagen synthesis and downregulation of collagen degradation. Cytokine signaling after topical application of exogenous GFs or injection of autologous GFs may mirror the interactions that occur during wound healing. 


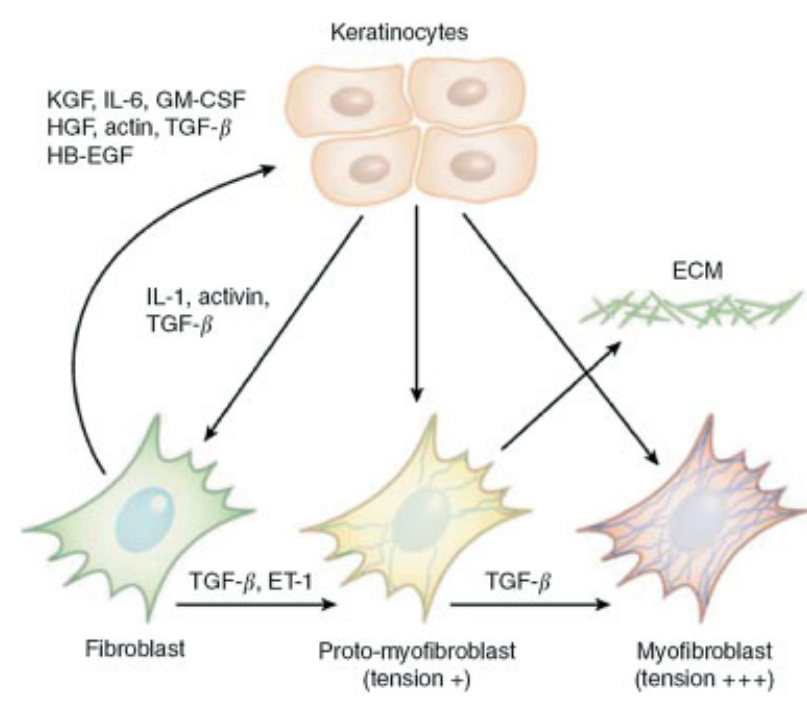

Fig. 3 Proposed mechanism of action and signaling cascade for growth factors and cytokines. Reproduced with permission from Fabi and Sundaram. ${ }^{7}$ ECM, extracellular matrix; EGF, epidermal growth factor; ET-1, endothelin 1; HGF, hepatocyte growth factor; IL-1, interleukin 1; IL-6, interleukin 6; KGF, keratinocyte growth factor; TGF, transforming growth factor;.

If topical GFs successfully penetrate the stratum corneum, they can bind to specific receptors on keratinocytes and initiate a signaling cascade. After GF-receptor binding, GFs secreted by the keratinocytes themselves stimulate fibroblasts to synthesize GFs that exert effects in the dermis. Fibroblast-derived GFs also stimulate keratinocyte proliferation, resulting in amplification of the initial signaling loop (-Fig. 3). Studies have shown minimal penetration of intact stratum corneum by hydrophilic molecules that have a molecular weight greater than $500 \mathrm{Da}^{16}$ GFs are large, hydrophilic molecules with a molecular weight of over $15,000 \mathrm{Da}$. Therefore, it is unlikely that they could penetrate intact epidermis in sufficient quantities to produce clinically significant effects. One route by which topical GFs could reach epidermal keratinocyte receptors is via hair follicles and sweat glands. Another consideration is that the barrier function of aging skin is somewhat compromised, and this may permit better penetration. Once GFs have traversed the stratum corneum, their interaction with specific receptors on keratinocytes can initiate a cytokine signaling cascade that affects fibroblasts and other cells in the dermis. The resultant collagenesis and remodeling of the ECM has been observed histologically, and can be correlated with the clinical results that are described below.

Injected PRP and its derivative, platelet-rich fibrin matrix (PRFM), contain GFs that can potentially exert effects through similar mechanisms. Their direct intradermal or subdermal injection bypasses the epidermal barrier, and could accelerate and/or enhance the clinical effects. ${ }^{17}$

\section{Topical Growth Factors and Cytokines}

Topical GFs are derived from a variety of sources including humans (epidermal cells, placental cells, foreskin, and colostrum), animals, plants, recombinant bacteria, and yeast. ${ }^{18}$

Nonrecombinant human GFs are commercially available in various topical formulations. They include a formulation containing cell culture medium collected from a line of dermal fibroblasts originating from neonatal foreskin (NouriCel-MD, SkinMedica, Allergan, Carlsbad, CA); and another containing processed skin cell proteins (PSP, Neocutis, Merz, Lausanne, Switzerland), comprising a mixture of cytokines, GFs, and antioxidants harvested from fetal fibroblast cell lysate. GFs derived from the secretions of the snail Cryptomphalus aspersa (SCA) are also commercially available (Tensage, Biopelle, Inc., Ferndale, MI, manufactured by Industrial Farmaceutica Cantabria, SA). Many clinical studies on topical GFs do not meet the highest evidence level criteria. Those of evidence level II or III are reviewed below ( - Table 3, levels of evidence).

In one clinical study, a GF serum containing NouriCel-MD (TNS recovery complex, SkinMedica, Allergan) was applied to the facial skin of 14 patients twice daily for 60 days, with the aim of stimulating dermal remodeling. Patients were evaluated by a 9-point scale for clinical signs of photodamage, optical profilometry, and histopathologic evaluation of a punch biopsy from treated skin. Approximately $78.6 \%$ of patients with photodamaged skin showed clinical improvement at 60 days. Histopathologic examination revealed that $37 \%$ of patients had new collagen formation in the Grenz zone, and $27 \%$ showed epidermal thickening ${ }^{19}$ (-Fig. 4). A randomized, vehicle-controlled, double-blind study of the same GF

Table 3 ASPS evidence rating scale for therapeutic studies

\begin{tabular}{l} 
I: High-quality, multicentered or single-centered, randomized controlled trial with adequate power; or systematic review \\
of these studies (at least 100 study subjects) \\
II: Lesser quality randomized controlled trial; prospective cohort or comparative study; or systematic review of these studies \\
III: Retrospective cohort or comparative study; case-control study; or systematic review of these studies \\
\hline IV: Case series with pre/posttest; or only posttest \\
V: Expert opinion developed via consensus process; case report or clinical example; or evidence based on physiology, \\
bench research or "first principles"
\end{tabular}




\title{
Collagen Deposition in Epidermis
}

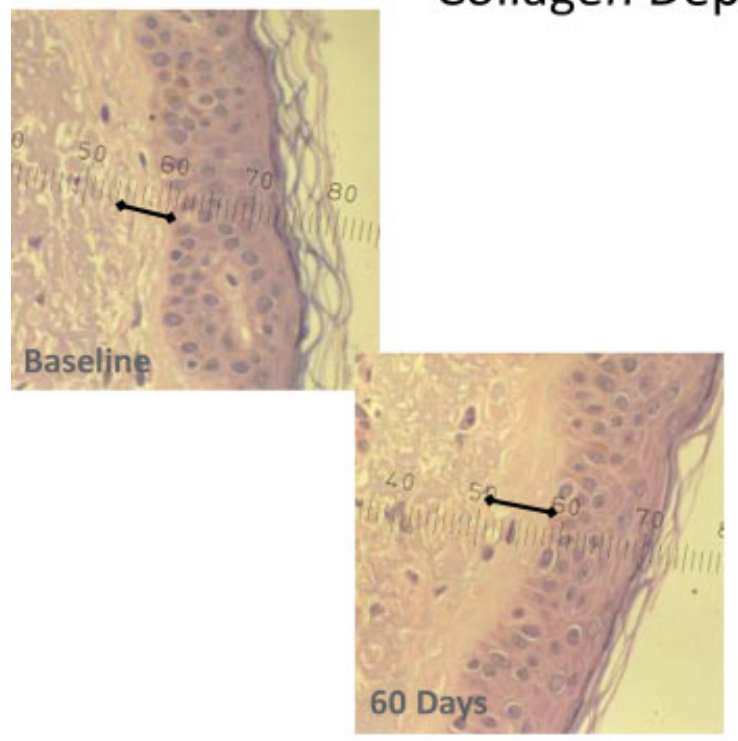

\author{
Biopsy show ing increase in \\ Grenz zone collagen
}

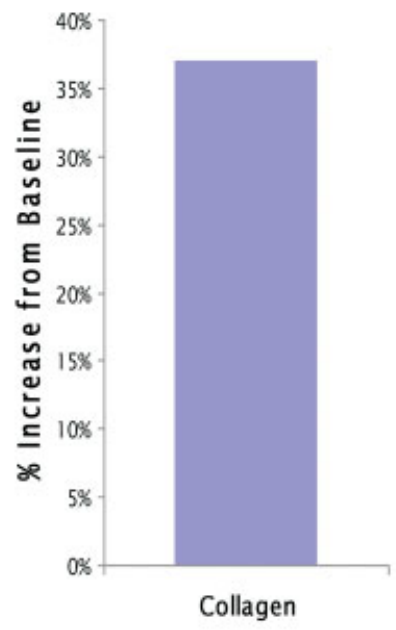

Hema Sundaram, M.D.

Fig. 4 Results after application of a topical growth factor and cytokine mixture derived from human fibroblast secretions (TNS Recovery Complex, SkinMedica, Allergan, Carlsbad, CA) twice daily for 60 days in 14 patients. The black bars on the photomicrographs show the thickness of the Grenz zone of the dermis. The bar graph shows a mean increase of over 35\% in thickness of Grenz zone in the 14 patients studied. Adapted from Fitzpatrick and Rostan. ${ }^{19}$

mixture in 60 patients with a mean age of 55 years and facial photodamage (mild to moderate in 48 subjects and severe in 12 subjects) showed improvement in preauricular fine rhytids, skin tone and texture, and hyperpigmentation $(p=0.012 \text { at } 3 \text { months })^{20}$ ( $\mathbf{- F i g . 5 A - C}$ ). Patient and physician assessments were performed at baseline and at 3 and 6 months. Optical profilometry of silicone skin surface impressions showed improvements in skin roughness ( $p=0.045$ at 3 months).

The antiaging potential of PSP (Bio-restorative Skin Cream, Neocutis, Merz) was investigated in a study of 12 subjects who applied the cream twice daily to the entire face for 6 months. ${ }^{21}$ Results were assessed by standardized photography, and clinical evaluation of treated skin using a 5-point visual wrinkle scale. Histopathologic examination of preauricular skin was performed before and after treatment. After treatment, the mean clinical improvements in appearance of periorbital and perioral wrinkles were 33 and 25\%, respectively. Increased fibroblast density in the superficial dermis and moderate increases in epidermal thickness were seen histologically after 6 months. Ultrastructural changes consistent with new collagen formation were shown by electron microscopy.

In a two-center, double-blind, randomized 14-week study, 25 patients with moderate-to-severe facial photodamage were treated for 12 weeks with an emulsion containing $8 \%$ SCA and a liquid serum containing $42 \%$ SCA (Tensage serum, Biopelle) on one side of the face, and with a placebo cream on the other side. ${ }^{22}$ Silicone skin impressions of periocular rhytides were performed at baseline and after 12 weeks of treatment. Patient and physician assessments were performed at baseline and at 8,12, and 14 weeks. At 12 weeks, there was significant improvement in coarse periocular rhytides on the side treated with the GF active $(p=0.03)$. Skin texture was also improved at 8 and 12 weeks, and remained improved 2 weeks after discontinuing the product, at 14 weeks (-Fig. 6A, B).

An interesting new development is the generation of GFs from cultured neonatal human dermal fibroblasts that demonstrate multipotent behavior under conditions of hypoxia intended to simulate the fetal environment. These fibroblasts express and secrete GFs including KGF, VEGF, and IL-8, together with stem cell associated proteins. It is hypothesized that this may induce a more regenerative pattern of collagenesis, with higher expression of types III and $\mathrm{V}$ relative to type I collagen, as is seen in the fetus where skin healing is scarless. An open-label comparative study of a lotion containing conditioned cultured medium produced by these multipotent fibroblasts (ReGenica, Suneva Medical, San Diego, CA) was performed in 49 subjects receiving ablative Erbium laser resurfacing of the periocular and perioral regions. ${ }^{23}$ At day 7 following laser resurfacing, there was greater reduction in periocular and perioral erythema with the active lotion than with placebo as determined by blinded, clinical evaluation of photographs and by Mexameter (CK Electronic, Cologne, Germany) measurements. There was also a statistically significant reduction in rescue petrolatum use in subjects treated with the active lotion $(p=0.0004)$. A split-face evaluation of 42 subjects undergoing combination ablative and nonablative laser procedures showed a more rapid return 

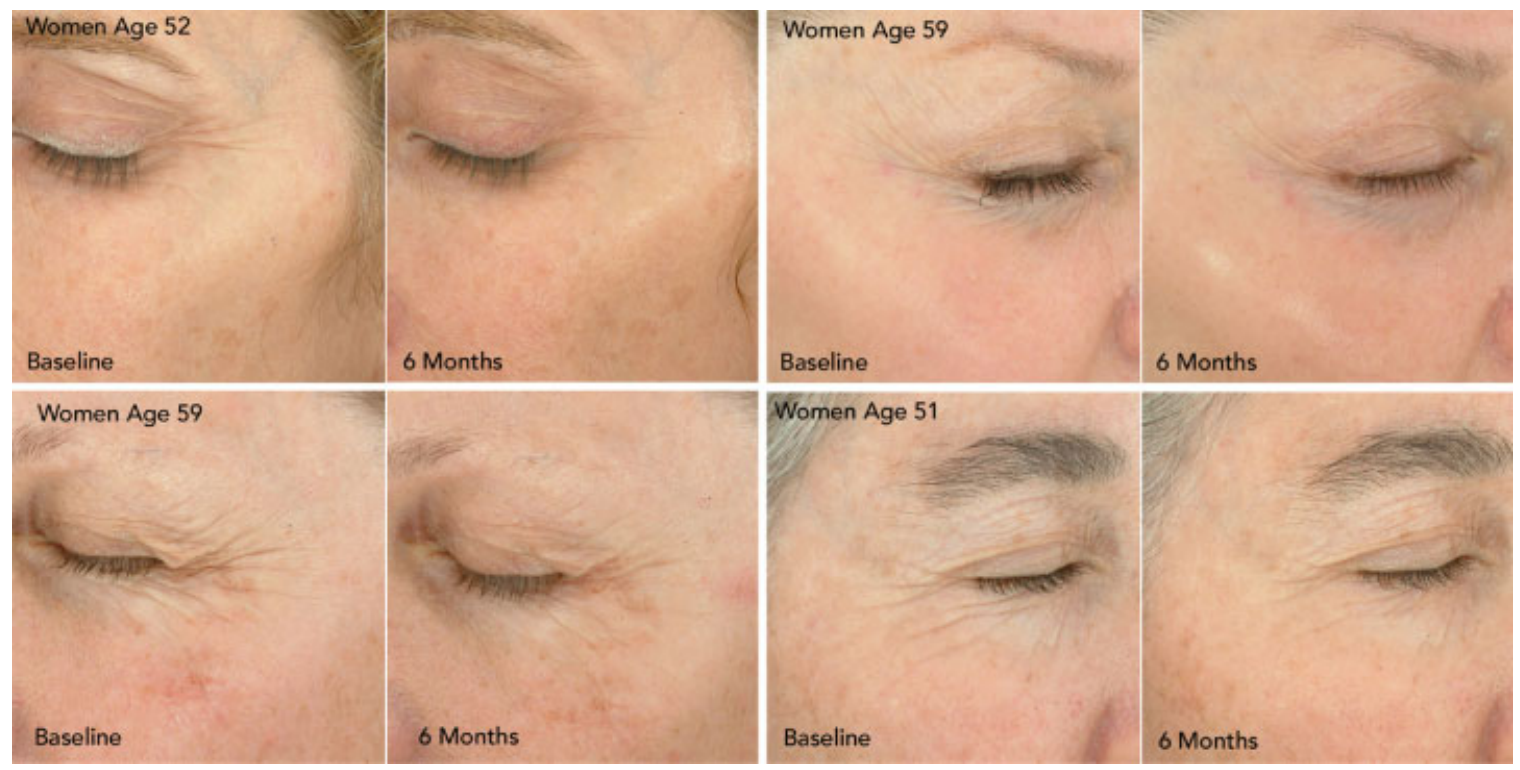

Fig. 5 (A) Clinical results after application of a topical, human fibroblast-derived growth factor and cytokine mixture (TNS Recovery Complex) twice daily for 60 days. Improvement in fine rhytids and mottled hyperpigmentation is seen. (B) Silicone skin surface impressions from the periocular region of patients treated with the topical growth factor and cytokine mixture. There is a visible reduction in number and depth of rhytids after 6 months of use. (C) Optical profilometry analysis of the silicone skin surface impressions. A statistically significant reduction in fine and coarse rhytids is seen with the active at 3 months and a trend toward significance at 6 months. Reproduced with permission from Fabi and Sundaram. ${ }^{7}$

to normal skin barrier function with gel containing the active GF formulation, as measured by transepidermal water loss readings $(p \leq 0.05) \cdot{ }^{23}$

\section{Injectable Growth Factors and Cytokines}

\section{Platelet-Rich Plasma}

The primary function of platelets is to control blood loss following vascular injury. The interaction between platelets and plasma proteins-notably fibrin formed from fibrinogen by the protease, thrombin-causes fibrin clot formation. The clot is a reservoir of GFs, which are discharged into plasma from the alpha-granules of platelets when they are activated and destroyed during wound healing and tissue regeneration. The rationale of PRP is to concentrate and provide these GFs directly to a target tissue, such as aging skin; or injured muscle, tendon, or cartilage. Typically, the concentration of platelets in PRP may be 5 to 10 times the normal platelet concentration in blood. At the time of writing, PRP is approved by the US Food and Drug Administration (FDA) for combination with allograft or autograft bone before implantation and, in the case of some PRP separation systems, for treatment of nonhealing diabetic ulcers. Injection of PRP for indications such as skin rejuvenation is off FDA labeling.

Injection of PRP allows direct delivery of GFs to the dermis, and the hypodermis if desired. As the stratum corneum is bypassed, efficacy does not depend on transepidermal penetration of the actives, as it does with topical GFs. The signal amplification cascade from epidermal keratinocytes to dermal fibroblasts, described earlier when GFs are applied topically, could also occur when they are injected.
To prepare PRP, 15 to $60 \mathrm{~mL}$ of whole blood are drawn from the patient by venipuncture, into tubes containing $1 \mathrm{mg} / \mathrm{mL}$ ethylene diamine tetra acetic (EDTA) acid disodium or acid citrate dextrose (ACD) solution as an anticoagulant. ${ }^{24}$ The autologous blood is centrifuged with specific force and duration-typically 1,100 to $1,200 \mathrm{~g}$ for 6 to 17 minutes-with the aim of separating its components without damaging platelets. Centrifugation separates and concentrates the erythrocytes, leukocytes, and platelets at various levels in the tube. The supernatant fraction that is rich in platelets is withdrawn into another tube and the platelets are activated, usually with calcium and bovine thrombin. This results in platelet degranulation, and extensive release of GFs. In some preparation protocols, leukocytes are added to the PRP (W-PRP); some include a second centrifugation step to obtain a plateletconcentrated plasma (PCP); and some use noncoagulating platelet-derived factor concentrate (PFC).

The use of patients' own platelets and GFs is an appealing aspect of PRP. However, its autologous nature introduces variability to its composition, creating challenges for both clinicians and researchers. ${ }^{25}$ The unclear therapeutic benefits of PRP are due in part to lack of standardized preparation protocols, and in part to the lack of controlled study data. Proponents of PRP cite suboptimal preparation as a reason for its unpredictable efficacy. Most clinical studies of PRP for skin rejuvenation are not of the highest evidence level, with a level of III, IV, or V being typical.

Tissue repair from the actives in PRP is a process involving a delicate balance of cells and GFs, whose interactions are still not entirely understood. ${ }^{26}$ There are significant variations in the composition of PRP obtained with the same protocol from 


\section{Skin Surface Impression of Periorbital Area}
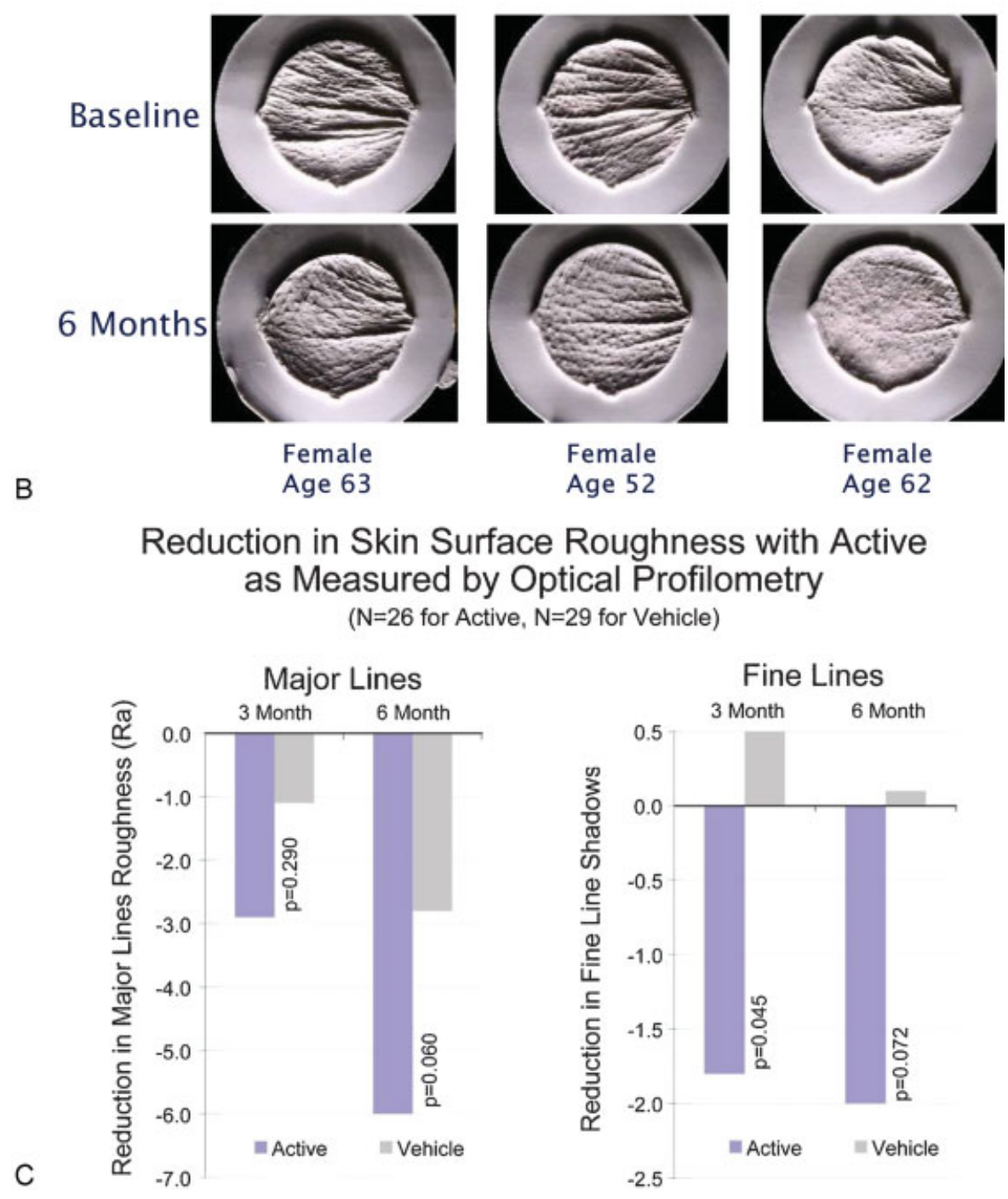

Female

Age 52

Female

Age 62

\section{Reduction in Skin Surface Roughness with Active as Measured by Optical Profilometry}

( $\mathrm{N}=26$ for Active, $\mathrm{N}=29$ for Vehicle)

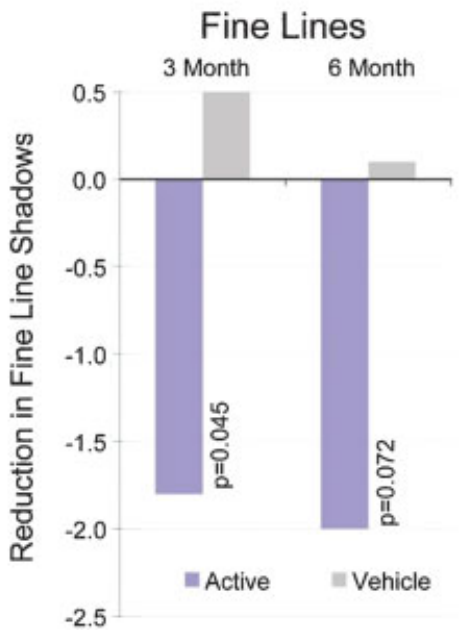

Fig. 5 (Continued)

different patients. Even blood draws at different times in the same patient result in variations. This variability is compounded by the multitude of protocols and devices available for preparing PRP. Protocol variations that can impact the final product include the size and shape of the containers used for blood collection, centrifugation, and injection; the anticoagulant used during blood collection; and the force and duration of centrifugation. Several variants of PRP can be produced even from the same blood specimen-including $\mathrm{W}$ PRP, PCP, and PFC, as described earlier. It is readily apparent that results reported from individual studies of PRP cannot be generalized to the whole genre of treatment.

When three commercially available PRP separation systems (MTF Cascade, Arteriocyte Magellan, and Biomet GPS III) were evaluated for the composition of PRP they generated from five healthy human subjects, different concentrations of
GFs and leukocytes were found. ${ }^{27}$ The GPS III and Magellan systems produced leukocyte-rich PRP, with increased concentrations of leukocytes, PDGF- $\alpha \beta$ PDGF- $\beta \beta$, and VEGF, whereas the Cascade system produced leukocyte-poor PRP. There was no significant difference between the three systems in platelet concentration; nor in levels of red blood cells, active TGF- $\beta 1$, or fibrinogen. Variability in the components of PRP and the resultant effects on dosage should be considered when evaluating the efficacy of single or sequential treatment sessions.

Araki et $\mathrm{al}^{24}$ aimed to optimize protocols for preparing human PRP and PCP, by establishing a reliable and practical method, using common laboratory equipment, to maximize platelet yield and concentration in plasma derived from blood volumes of 42 to $72 \mathrm{~mL}$. When thrombin and calcium are used during PCP preparation, this can polymerize fibrinogen and 

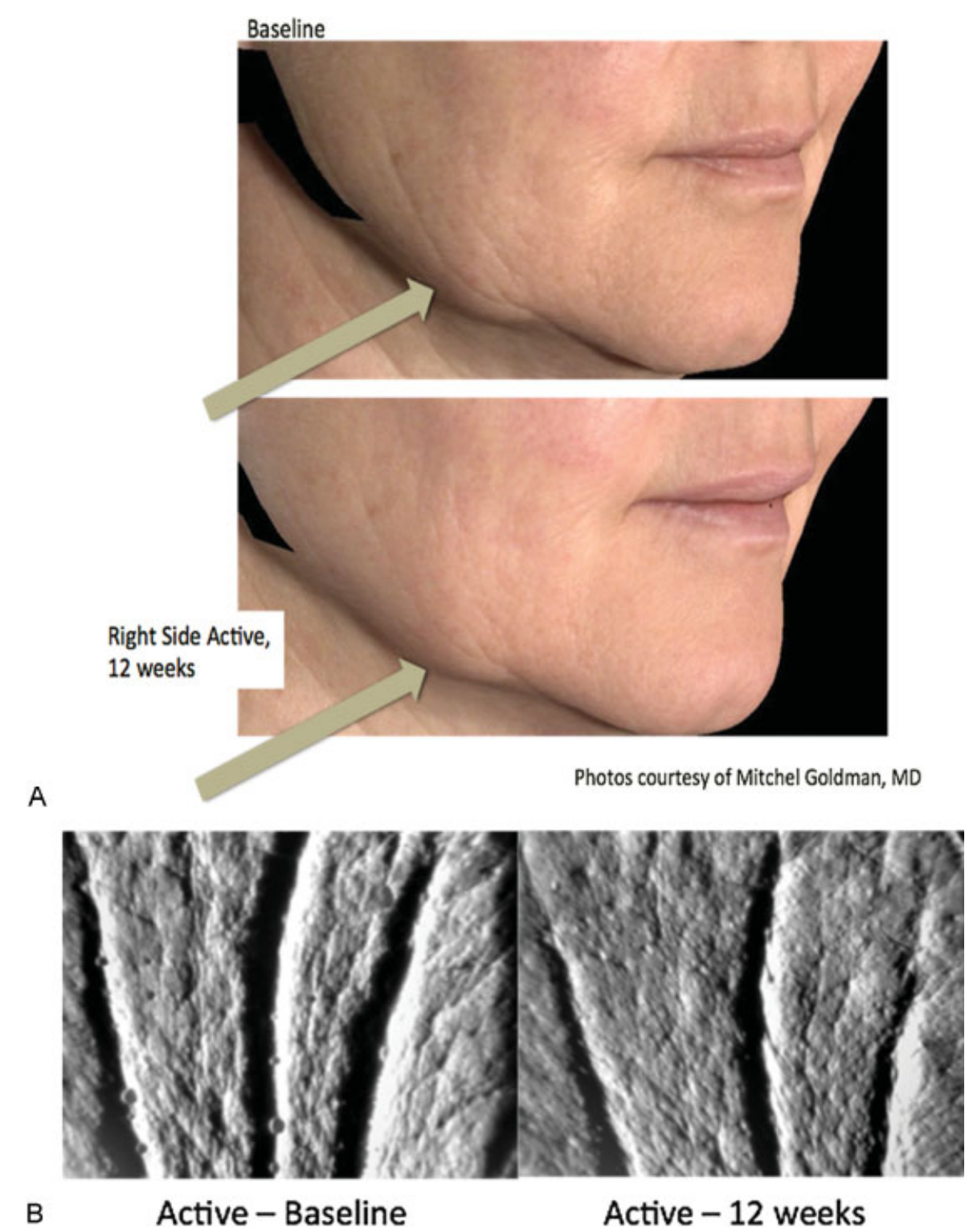

Fig. 6 (A) Before (top) and after (below) application of topical, snail-derived growth factor and cytokine mixtures (Tensage, Biopelle, Ferndale, MI) twice daily for 12 weeks. Courtesy of Mitchel Goldman, MD. (B) Silicone skin impressions of periocular rhytides at baseline (left) and after (right) application of topical, snail-derived growth factor and cytokine mixtures (Tensage, Biopelle, Inc., Ferndale, MI) twice daily for 12 weeks. There is a statistically significant difference between baseline and 12-week assessment of wrinkle depth. Courtesy of Biopelle. Inc.

result in the formation of fibrin glue, which is procoagulant and sometimes prevents the use of PCP for certain applications. Therefore, the investigators also designed a protocol for the preparation of PFC-which, as discussed previously, is noncoagulating. Whole blood was obtained 3 to 12 times from each of nine healthy donors and collected into conical tubes (15 mL; BD Falcon [BD Biosciences, San Jose, CA]) that contained one of two anticoagulants-EDTA (Wako Pure Chemical Industries, Ltd., Osaka, Japan) or ACD (Terumo, Shibuya, Tokyo; acid citrate:dextrose ratio of 10:1.5). The tubes containing blood were centrifuged for 10 minutes at $20^{\circ}$ C (Kubota 5900 centrifuge, Kubota Co., Tokyo, Japan) at various forces (17 values ranging from 30 to 2,330 g). Volume and hematological values were measured, and then the PRP was centrifuged again at a higher force, to precipitate the platelets at the bottom of the tube. The number of non- aggregated platelets and the concentration of PDGF-BB in the products were tabulated to assess efficiency of the protocol. Optimal PRP preparation was found to result from the use of EDTA as an anticoagulant, with centrifugation in a $15 \mathrm{~mL}$ conical tube at 230 to $270 \mathrm{~g}$ for isolation of PRP or at $70 \mathrm{~g}$ for isolation of W-PRP. Further precipitation of platelets, together with a substantial decrease in leukocyte concentration, occurred when PRP was centrifuged again for $10 \mathrm{mi}-$ nutes at 2,300 g or higher. After this second centrifugation, samples were divided into two parts, PCP and platelet-poor plasma (PPP). For one-tenth volume of PCP, nine-tenths volume of the supernatant PPP was removed and the platelet pellet was resuspended in phosphate-buffered saline (PBS), followed by platelet activation with thrombin. This resulted in a preparation with a platelet concentration up to 20 times that of whole blood. For one-tenth volume of PFC, all 
supernatant PPP was removed, one-tenth volume of PBS was added, and the platelet pellet was then resuspended, followed by platelet activation with thrombin. This preparation had a PDGF-BB concentration significantly higher than whole blood, PRP, and one-tenth volume PCP; although platelet concentrations were surprisingly similar to one-tenth volume PCP. The investigators concluded that removal of fibrinogen from plasma is crucial to obtain the maximal amount of platelet-derived GFs, and that replacement of PPP with PBS after strong centrifugation is a simple and efficient method to remove fibrinogen that may correlate with detectable therapeutic effects. They also commented that W-PRP platelet yield and obtained plasma volumes were less than those of PRP and PCP.

\section{Clinical and In Vitro Studies of Platelet-Rich Plasma}

Human case series, often small, provide anecdotal evidence that PRP has efficacy for skin rejuvenation. As with topical GFs, parallels have been drawn with the effects of the injectable GFs in PRP on wound healing. While this provides some bridging of evidence gaps, prospective, randomized, controlled trials with adequate power are required to raise the evidence to a higher level. Animal studies of PRP may be part clinical and part in vitro in their methodology. Care should be taken when extrapolating data to the in vivo, human scenario. As many of these studies assume a preexisting knowledge of protocols and the theory behind them, explanatory notes are provided below to aid in literature review.

In several studies investigating the effects of PRP on fibroblast-mediated repair of the dermis or of ligaments and tendons, attention has focused on the role of leukocytes, which are believed to change the GF profile in PRP. The potential effect on clinical efficacy of PRP is open to debate. PRP that contains a substantial proportion of leukocytes has been proposed by some as a therapeutic tool because of the theoretical risk of development of bacterial and/or immunological resistance to PRP. Others consider leukocytes to be a contaminant, and advise caution to avoid an inflammatory reaction between them and the exposed tissues. ${ }^{28-32}$ Leukocytes produce GFs such as VEGF that have antimicrobial and restorative effects during the wound healing response. However, they are also believed to increase tissue inflammation, because neutrophils and monocytes produce MMPs and ROS that can cause tissue damage and ECM degradation. A higher leukocyte concentration in PRP has been found to correlate with increased MMP gene expression, and the release of ROS and various proteases by neutrophils. ${ }^{33}$ Conversely, macrophages, derived from circulating monocytes, can aid in the removal of tissue debris and the initiation of tissue repair; in one study of rats, depletion of macrophages limited early healing processes, and compromised ligament strength. ${ }^{34}$

In summary, there may be a delicate balance between the presence of leukocytes in PRP and its effects on the target tissue. There is controversy regarding the relative benefits of leukocyte-poor versus leukocyte-rich products; and no consensus on the optimal concentration of leukocytes, which may fall within a narrow range. ${ }^{35}$ It is perhaps noteworthy that a recent evidence level I clinical trial by Gosens et al $^{36}$ found that leukocyte-enriched PRP outperformed corticosteroids in the treatment of chronic lateral epicondylitis.

Kawazoe and Kim investigated the importance of white blood cell inclusion in PRP, in a small case series of nude mice. PRP, optimally centrifuged at 2,600 rpm for 6 minutes, or $\mathrm{W}$ PRP containing all leukocytes, centrifuged for 10 minutes at $1,800 \mathrm{rpm}$, was injected into the auricles of the mice. Injections were also performed with PPP or saline (concentration unspecified) as a control. The investigators reported a range of five to nine mice in each study group. Injection sites were biopsied and processed for histopathological examination 2 weeks after injection. The investigators also sought to determine whether efficacy of W-PRP could be increased by the addition of basic fibroblast growth factor (bFGF), as this has a high binding affinity for fibrin and fibrinogen and can regulate adhesion of fibroblasts and other cells to injured tissue. There are reports from Japan that wound healing is accelerated by topical application of bFGF to skin ulcers and defect injuries ${ }^{37}$; and studies demonstrating that local injection of bFGF preparations into wound sutures results in clean wound healing. ${ }^{38,39}$ In the Kawazoe and Kim study, it was found that injection of W-PRP gave greater tissue augmentation and greater output of bFGF and VEGF than injection of PRP. Further tissue thickening occurred in a concentrationdependent manner when bFGF was added to the W-PRP, with greatest tissue augmentation observed when the bFGF concentration was $100 \mu \mathrm{g} / \mathrm{mL}$. In the mouse auricles injected with W-PRP plus bFGF, there was also a significant increase in the number of cells staining positively for $\alpha$ smooth muscle actin ( $\alpha$-SMA), which is a long-term marker of myofibroblast formation. These researchers and others consider this relevant because they hypothesize that PRP-induced differentiation of dermal fibroblasts into myofibroblasts promotes wound contraction and thus enhances wound healing.

Yoshida et $\mathrm{al}^{40}$ further elucidated the role in tissue regeneration of a specific subtype of leukocyte-peripheral blood mononuclear cells (PBMCs), which include lymphocytes, monocytes, and macrophages. Previous studies have demonstrated that autologous platelet gel, a viscous form of PRP produced when platelet concentrate is combined with thrombin and calcium, can activate PBMCs to release proinflammatory cytokines, including IL-6. ${ }^{41}$ As IL-6 is known to stimulate collagen production by fibroblasts in the dermis and in ligaments, Yoshida et al hypothesized that coculture of PBMCs with platelets might increase the IL-6 production of PBMCs, and subsequent collagen production by ligament fibroblasts. Porcine fibroblasts were cultured on three-dimensional collagen scaffolds for 14 days with and without PBMCs. Bovine anterior cruciate ligament (ACL) fibroblasts exposed to PBMCs and cultured in the presence of porcine platelets and plasma showed an increase in IL-6 expression, type I, and type III procollagen gene expression $(p<0.05$ for each collagen type), collagen protein expression $(p<0.01)$, and cell proliferation $(p<0.01)$. However, addition of PBMCs to fibroblasts cultured without platelets did not yield these same results. Nor did addition of PBMCs to fibroblasts cultured with PPP which, as evident from the preparation method described 
above, contains all the plasma proteins present in PRP, but no platelets. On the basis of these results, the investigators postulate that the interaction between platelets and PBMCs leads to an IL-6 mediated increase in collagen expression by ACL fibroblasts, and that this mechanism of action can be extrapolated to dermal fibroblasts.

There were different findings from another study, in which porcine mesenchymal stem cells isolated from PBMCs and cocultured with porcine ACL fibroblasts in the absence of platelets mediated increased fibroblast migration and expression of types I and III collagen at day $14{ }^{42}$ This suggests that PBMCs may have the potential to enhance fibroblast migration, proliferation, and collagen production in different ways, not all of which are dependent on interaction with platelets and the GF signaling cascades that ensue.

\section{Platelet-Rich Fibrin Matrix}

The rationale for development of PRFM as a variant of PRP is that unpredictable efficacy and longevity of results with PRP have been attributed to the short lifespan of GFs in the tissue after injection. It has been shown that GFs such as TGF- $\beta$ and PDGF are released immediately from the platelets in PRP, and are at a significantly reduced level when measured at days 3 , 7, and $14 .{ }^{43}$ This finding may explain the transient effect of PRP on wound healing, which has been documented in several studies. ${ }^{44-46}$ The aim of PRFM is to provide a fibrin scaffold that allows a more physiologic, sustained release of higher levels of GFs after the initial injection, to produce more efficient tissue regeneration.

Like PRP, autologous PRFM is prepared from peripheral whole blood, drawn into collection tubes that may contain thixotropic separator gel. After centrifugation, the supernatant plasma/platelet suspension is transferred to a second tube containing calcium chloride, which initiates the polymerization of fibrin. After the polymerization process is complete, the PRFM should be injected within 10 to 12 minutes, before full polymerization makes the preparation difficult to pass evenly through a syringe and needle.

PRFM is a more dilute preparation than PRP, with approximately two to three times the concentration of platelets in whole blood. Its greater stiffness than PRP, once fully polymerized, is hypothesized to facilitate more accurate implantation and longer persistence in tissue. Circumstantial evidence is provided by a study of bovine PRFM, which stimulated proliferation of cultured ovine tendon cells and also their synthesis of VEGF. This correlated with an increase in cellular density and neovascularization after injection into living sheep tendons. ${ }^{47}$ In another study, PRFM stimulated proliferation of cultured human dermal fibroblasts, providing sustained release for over 7 days of PDGF, VEGF, TGF- $\beta$, and IGF-1 and protecting against proteolytic degradation of endogenous fibrogenic factors considered important for wound healing. ${ }^{48,49}$

\section{Clinical Studies of Platelet-Rich Fibrin Matrix}

In a case series of four healthy adults, PRFM was prepared from $9 \mathrm{~mL}$ of autologous blood using a proprietary system (Selphyl; Aesthetic Factors, Wayne, NJ) and injected into the dermis and subdermis of human upper arm skin. ${ }^{50}$ By 7 days, histopathological examination showed fibroblast activation and significant new collagen deposition. By day 19 , significant angioneogenesis and adipogenesis were present, without any evidence of cellular atypia. By 10 weeks, the fibroblast response subsided, with new collagen and blood vessels still evident in the dermis (-Fig. 7). These histologic findings support clinical observations of soft-tissue augmentation, such as a prospective study of 15 patients, ${ }^{51}$ demonstrating that PRFM injected into the deep dermis or immediate subdermis produced significant improvement in deep nasolabial folds within 14 days. Results were sustained throughout the 12-week duration of the study (-Fig. 8).

These data have expanded the clinical applications of PRFM to dermal and subdermal augmentation of rhytids, folds and depressions; acne scar effacement; and acceleration of wound healing after rhytidectomy. PRFM has also been used in combination with autologous fat transfer and around implants. ${ }^{52,53}$ In a retrospective review by Sclafani of 50 patients with at least 3 months of follow-up after injection of PRFM for deep nasolabial folds, midface volume loss, superficial rhytides, and acne scars, patients typically

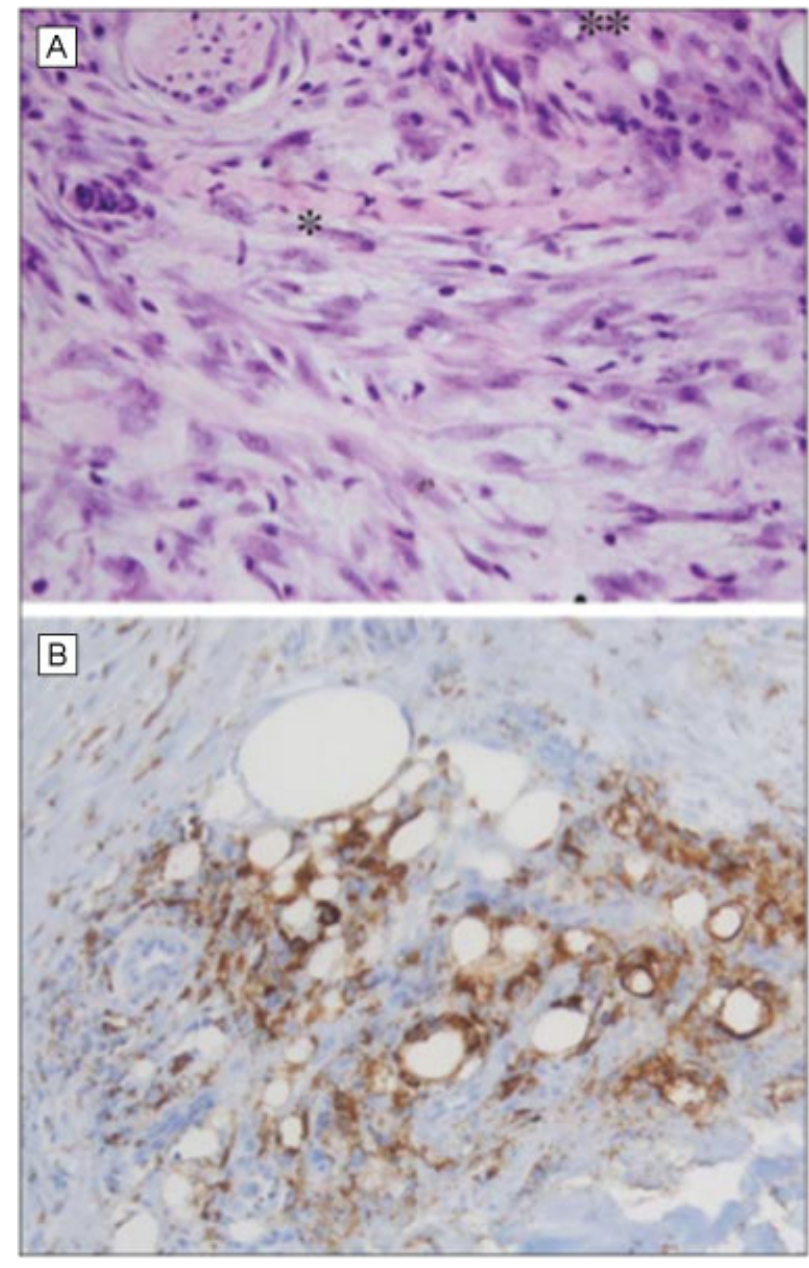

Fig. 7 Cellular changes on histopathological examination after injection of platelet-rich fibrin matrix (PRFM, Selphyl; Aesthetic Factors, Wayne, NJ) into upper arm dermis and subdermis. Adapted from Sclafani and McCormick. ${ }^{50}$ 

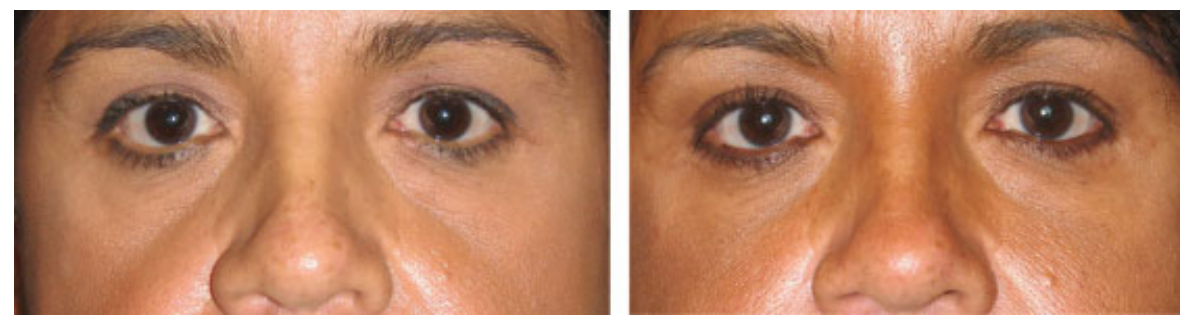

Fig. 8 Before and 6 weeks after submuscular injection of 2 cc platelet-rich fibrin matrix (PRFM, Selphyl; Aesthetic Factors, Wayne, NJ) to each lower eyelid. Adapted from Sclafani. ${ }^{52}$

underwent an average of 1.6 treatments (range, 1-5 treatments). Most were satisfied with their results, perceiving noticeable results by 5 to 7 days after treatment, with $90 \%$ noticing continued improvement until 2 to 4 weeks after treatment. ${ }^{53}$ Approximately $10 \%$ felt the changes were minimal after the first treatment and were retreated, and $80 \%$ of those patients ultimately noticed improvement with retreatment. The investigator attributed this lack of response on initial treatment to undercorrection, and advocates overcorrection at first injection, as some of the injected volume comprises plasma fluid that is rapidly resorbed over a 12 hour period. There were no serious or long-lasting adverse effects. Postinjection swelling lasted for up to 5 days; and a low incidence of ecchymosis was reported, except in some patients treated periorbitally, who experienced ecchymoses lasting up to 14 days. No nodules, papules, inflammatory reactions, or infection were seen.

In another case series, a study by Katz (in preparation), qualitative and quantitative changes from PRFM (Selphyl) were evaluated after 10 patients received injection to the infraorbital hollows (tear troughs) at baseline, and 5 of them also received injection 6 weeks later. Patients demonstrated clinical improvement in volume, depth, and texture of the infraorbital hollows 3 months and 6 months after injection. This was corroborated by quantitative analysis using standardized, digital three-dimensional imaging (3D LifeViz, Cos-
moFrance, Miami, FL/Quantificare, San Mateo, CA). PRFM treatment was well-tolerated, and no serious or long-lasting adverse events were observed (-Fig. 9).

One of the authors (H.S.) has observed variable longevity of results after PRFM injection, with no specific patient characteristics currently identifiable as predictors of efficacy. The treatment has been of benefit for patients in whom periocular injection of hyaluronic acid fillers is contraindicated due to a tendency to develop recurrent swelling. Anecdotally, the author finds that some of these patients report a history of periocular surgery; or a previous, initial episode of swelling after suboptimal periocular filler injection (e.g., behind the orbital septum, presumably with subsequent lymphatic outflow obstruction) that is followed by propensity for swelling even after the filler is removed. The author also finds PRFM of value for those patients who philosophically prefer autologous treatments to alloplastic ones, or a combination of the two types of treatment. ${ }^{54}$ The use of a blunt microcannula for submuscular injection, in combination with a narrow gauge needle for intradermal injection, provides a layered treatment paradigm for efficient delivery of actives to the target tissue with decreased incidence of ecchymosis and patient discomfort. Patients who respond well tend to show marked improvement in skin texture and reflectance, with mild-to-moderate volumetric improvement (-Fig. 10A, B).
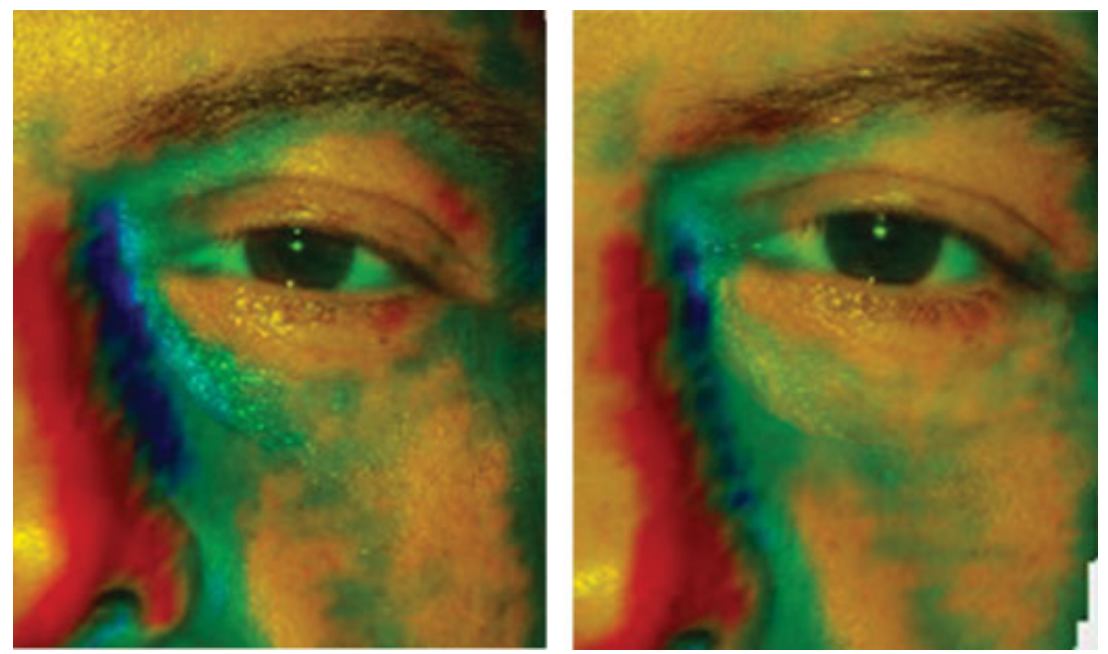

Fig. 9 Three-dimensional analysis (3D LifeViz, Quantificare, Miami, FL) for volume, depth, and surface area changes before (left) and after (right) injection of platelet-rich fibrin matrix to the tear troughs. Areas of volume augmentation are indicated in orange/yellow. Less augmented areas are less elevated, and indicated in green/blue. Image courtesy of Bruce Katz, MD. 
A
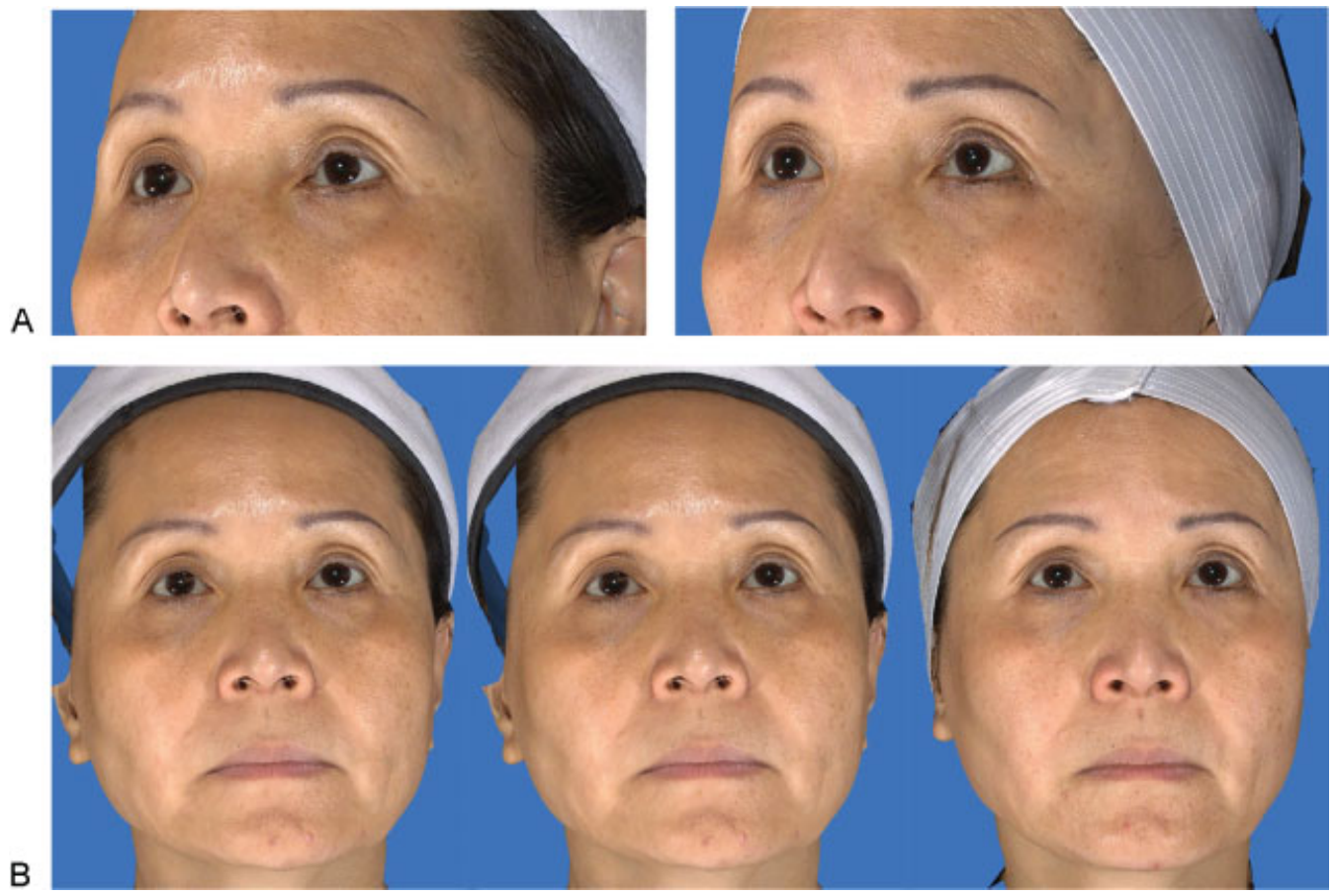

Fig. 10 (A) A 57-year-old woman before (left) and after (right) submuscular injection of 2 cc platelet-rich fibrin matrix (PRFM) (Selphl, Aesthetic Factors, Wayne, NJ) to each lower eyelid using a 27 G 38 mm blunt microcannula, followed by intradermal injection of 0.5 cc PRFM to each side using a $30 \mathrm{G}$ needle. The image on the right was taken 94 days after the first treatment session and 73 days after the second session. On a 5-point assessment scale for patient satisfaction, the patient reported that she was "Extremely Satisfied" (the highest score on the scale) with the result. Three-dimensional imaging with Canfield Vectra system. Courtesy of Hema Sundaram, MD. (B) Same patient before (left) and after (middle and right) injection of 2.5 cc PRFM (Selphl) to each lower eyelid. Middle image is 21 days after the first treatment session. Right image is 94 days after the first session and 73 days after the second session. Threedimensional imaging with Canfield Vectra system. Courtesy of Hema Sundaram, MD.

\section{Adverse Effects and Safety Considerations}

All topically applied products carry the risk of irritant or allergic contact dermatitis, as do injectable preparations of PRP, which rely on animal-based thrombin and other additives. Because some malignant cells have receptors for certain GFs, and some GFs may increase cellular proliferation, there has been concern as to whether GFs might have the potential for tumorigenesis or promotion of cellular atypia. ${ }^{55,56}$ Others postulate that exogenous GFs have a normalizing effect on the growth and differentiation of target cells. Studies of the effects of individual GFs on animal skin and on human tumor cells have shown conflicting results. The validity of extrapolating these data to topical or injectable application of GF mixtures to human tissue remains to be clarified.

In one study, EGF, TGF- $\alpha$ and suramin (GF inhibitor) were applied to murine skin for nine days. It was found that TGF- $\alpha$ increased creatine phosphokinase (CPK) activity. EGF and TGF- $\alpha$ both induced a transition from the CPK MM to CPK BB isoenzyme. ${ }^{56}$ The significance of these findings is that the phosphocreatine/CPK system is believed to play an important role in the normal physiology of skin and in pathophysiological conditions such as psoriasis and carcinogenesis. Histopathological evaluation showed abnormal differentiation and distribution of keratinocytes. In a study of human tumor cells using the reverse transcriptase polymerase chain reaction, VEGF expression was found in all 15 cell lines that were examined, while the VEGF receptor, KDR, was detected only in three melanoma cell lines. ${ }^{55}$ Exogenously added VEGF (10 $\mathrm{ng} / \mathrm{mL}$ ) was able to stimulate up to $40 \%$ increased proliferation in these melanoma cells. In contrast, Graeven et al found exogenous VEGF had no significant effects on melanoma cell proliferation or on production of a transcriptional target for VEGF. ${ }^{57}$ And another study of human tumor cells, including squamous cell carcinomas of the head and neck and melanomas, found that VEGF treatment of tumor cells expressing the VEGFR-1 receptor actually inhibited cell proliferation and migration. ${ }^{58}$

To date, there have been no investigations of sufficient evidence level to indicate that topical or injectable GFs have either a stimulatory or inhibitory role in human carcinogenesis. An evidence-based approach requires controlled studies of balanced mixtures of multiple GFs that are applied topically or via injection to human tissue, rather than extrapolation from anecdote, or from animal studies that employ supraphysiological concentrations of one or a few GFs. Production and activity of the body's endogenous GFs are closely controlled by positive and negative feedback mechanisms. It is reasonable to infer that autologous and exogenous GF mixtures with a similar composition may be in a similar state of physiological balance, and also subject to some of the same control mechanisms. ${ }^{8}$ Our ethical responsibility toward patients mandates continuous monitoring of the safety of all therapeutic interventions. This is particularly so for aesthetic 
treatments, where there is essentially no benefit that can justify any significant risk. We recommend that the balance between efficacy and safety should be monitored with particular vigilance for variants of PRP that are modified by superconcentration, addition of significant levels of potent mitogenic cytokines such as bFGF, and VEGF, and other strategies intended to maximize cellular proliferation.

\section{Conclusion}

Topical and injectable GFs and cytokines have the potential to address skin aging through stimulation of cell regeneration. Analysis of the biochemical and structural changes that occur as skin ages has led to the observation that skin aging has some parallels with extensive acute and chronic skin wounding. The defined role of GFs in healing of skin wounds allows a parallel model to be developed for the role of GFs in skin rejuvenation. A limited number of controlled studies demonstrate that topically applied GFs can stimulate collagenesis and epidermal thickening; and that this is associated with clinical improvement in signs of photoaging. The use for skin rejuvenation of injectable GFs in PRP and its derivatives, such as PRFM, is still in an early stage. Although some reports are promising, substantial clinical data with an adequate evidence level remain to be accrued.

As with all aesthetic treatments, the safety, efficacy, tolerability, and stability of GF formulations are a priority. Challenges to optimizing these criteria include the inherent instability of GFs when not in their original environment. Surfactants, oils, and other excipients in topical formulations can denature and inactivate proteins, including GFs. Additives to PRP may also affect bioavailability and activity of the GF actives. Biological synthesis of GFs may be considered preferable to obtain proteins with a native or close-to-native secondary and tertiary molecular structure, to facilitate interactions with receptors in the target tissue. ${ }^{8}$ However, variations in composition of GF formulations are inevitable when they are biologically synthesized, and when different protocols are used for isolation of the actives. An evidencebased approach to evaluation of clinical effects requires placebo- and vehicle-controlled studies of appropriate design and power to generate high-quality data. A better understanding of mechanisms of penetration, release and activity of GFs will allow the development of more standardized treatment protocols, and logical guidelines regarding the number of treatments and treatment intervals that are indicated for skin rejuvenation.

Despite these caveats, the study of topical and injectable GFs remains fruitful and fascinating. Perhaps the most exciting thought is that ongoing research will ultimately advance our general understanding of dermal signaling mechanisms. This could provide deeper and more global insights into the mechanism of action of hyaluronic acid fillers-now increasingly suspected to possess restorative properties that could also be mediated by $\mathrm{GFs}^{59,60}$-and the potential for synergistic combination of GFs with them, other alloplastic fillers, and other modalities such as lasers and energy-based devices.

\section{References}

1 Schwartz E, Cruickshank FA, Christensen CC, Perlish JS, Lebwohl M. Collagen alterations in chronically sun-damaged human skin. Photochem Photobiol 1993;58(6):841-844

2 Quan T, He T, Kang S, Voorhees JJ, Fisher GJ. Solar ultraviolet irradiation reduces collagen in photoaged human skin by blocking transforming growth factor-beta type II receptor/Smad signaling. Am J Pathol 2004;165(3):741-751

3 Yamamoto Y, Gaynor RB. Therapeutic potential of inhibition of the NF-kappaB pathway in the treatment of inflammation and cancer. J Clin Invest 2001;107(2):135-142

4 Martin P. Wound healing-aiming for perfect skin regeneration. Science 1997;276(5309):75-81

5 Hensley K, Floyd RA. Reactive oxygen species and protein oxidation in aging: a look back, a look ahead. Arch Biochem Biophys 2002;397(2):377-383

6 Babu M, Wells A. Dermal-epidermal communication in wound healing. Wounds 2001;13(5):183-189

7 Fabi S, Sundaram H. Growth Factors in Cosmeceuticals. In: Farris P, ed. Cosmeceuticals in Cosmetic Practice. New Jersey, NY: Wiley; 2014

8 Sundaram H, Mehta RC, Norine JA, et al. Topically applied physiologically balanced growth factors: a new paradigm of skin rejuvenation. J Drugs Dermatol 2009;8(5, Suppl Skin Rejuvenation):4-13

9 Russell RP, Apostolakos J, Hirose T, Cote MP, Mazzocca AD. Variability of platelet-rich plasma preparations. Sports Med Arthrosc 2013;21(4):186-190

10 Rokhsar CK, Lee S, Fitzpatrick RE. Review of photorejuvenation: devices, cosmeceuticals, or both? Dermatol Surg 2005;31(9, Pt 2): 1166-1178, discussion 1178

11 Varani J, Warner RL, Gharaee-Kermani M, et al. Vitamin A antagonizes decreased cell growth and elevated collagen-degrading matrix metalloproteinases and stimulates collagen accumulation in naturally aged human skin. J Invest Dermatol 2000;114(3): 480-486

12 El-Domyati M, Attia S, Saleh F, et al. Intrinsic aging vs. photoaging: a comparative histopathological, immunohistochemical, and ultrastructural study of skin. Exp Dermatol 2002;11(5):398-405

13 Mori Y, Hatamochi A, Arakawa M, Ueki H. Reduced expression of mRNA for transforming growth factor beta (TGF beta) and TGF beta receptors I and II and decreased TGF beta binding to the receptors in in vitro-aged fibroblasts. Arch Dermatol Res 1998;290(3):158-162

14 Eming SA, Krieg T, Davidson JM. Inflammation in wound repair: molecular and cellular mechanisms. J Invest Dermatol 2007; 127(3):514-525

15 Moulin V. Growth factors in skin wound healing. Eur J Cell Biol 1995;68(1):1-7

16 Mehta RC, Fitzpatrick RE. Endogenous growth factors as cosmeceuticals. Dermatol Ther 2007;20(5):350-359

17 Cheng M, Wang H, Yoshida R, Murray MM. Platelets and plasma proteins are both required to stimulate collagen gene expression by anterior cruciate ligament cells in three-dimensional culture. Tissue Eng Part A 2010;16(5):1479-1489

18 Bonin-Debs AL, Boche I, Gille H, Brinkmann U. Development of secreted proteins as biotherapeutic agents. Expert Opin Biol Ther 2004;4(4):551-558

19 Fitzpatrick RE, Rostan EF. Reversal of photodamage with topical growth factors: a pilot study. J Cosmet Laser Ther 2003;5(1):25-34

20 Mehta RC, Smith SR, Grove GL, et al. Reduction in facial photodamage by a topical growth factor product. J Drugs Dermatol 2008; 7(9):864-871

21 Hussain M, Phelps R, Goldberg DJ. Clinical, histologic, and ultrastructural changes after use of human growth factor and cytokine skin cream for the treatment of skin rejuvenation. J Cosmet Laser Ther 2008;10(2):104-109

22 Fabi SG, Cohen JL, Peterson JD, Kiripolsky MG, Goldman MP. The effects of filtrate of the secretion of the Cryptomphalus aspersa on photoaged skin. J Drugs Dermatol 2013;12(4):453-457 
23 Kellar RS, Hubka M, Rheins LA, Fisher G, Naughton GK. Hypoxic conditioned culture medium from fibroblasts grown under embryonic-like conditions supports healing following post-laser resurfacing. J Cosmet Dermatol 2009;8(3):190-196

24 Araki J, Jona M, Eto $\mathrm{H}$, et al. Optimized preparation method of platelet-concentrated plasma and noncoagulating platelet-derived factor concentrates: maximization of platelet concentration and removal of fibrinogen. Tissue Eng Part C Methods 2012;18(3): 176-185

25 Zimber MP, Mansbridge JN, Taylor M, et al. Human cell-conditioned media produced under embryonic-like conditions result in improved healing time after laser resurfacing. Aesthetic Plast Surg 2012;36(2):431-437

26 Cho HS, Song IH, Park SY, Sung MC, Ahn MW, Song KE. Individual variation in growth factor concentrations in platelet-rich plasma and its influence on human mesenchymal stem cells. Korean J Lab Med 2011;31(3):212-218

27 Castillo TN, Pouliot MA, Kim HJ, Dragoo JL. Comparison of growth factor and platelet concentration from commercial platelet-rich plasma separation systems. Am J Sports Med 2011;39(2): 266-271

28 Mazzocca AD, McCarthy MB, Chowaniec DM, et al. Platelet-rich plasma differs according to preparation method and human variability. J Bone Joint Surg Am 2012;94(4):308-316

29 Moojen DJ, Everts PA, Schure RM, et al. Antimicrobial activity of platelet-leukocyte gel against Staphylococcus aureus. J Orthop Res 2008;26(3):404-410

30 Dohan Ehrenfest DM, Rasmusson L, Albrektsson T. Classification of platelet concentrates: from pure platelet-rich plasma (P-PRP) to leucocyte- and platelet-rich fibrin (L-PRF). Trends Biotechnol 2009;27(3):158-167

31 Han B, Woodell-May J, Ponticiello M, Yang Z, Nimni M. The effect of thrombin activation of platelet-rich plasma on demineralized bone matrix osteoinductivity. J Bone Joint Surg Am 2009;91(6): 1459-1470

32 McCarrel T, Fortier L. Temporal growth factor release from platelet-rich plasma, trehalose lyophilized platelets, and bone marrow aspirate and their effect on tendon and ligament gene expression. J Orthop Res 2009;27(8):1033-1042

33 Chamberlain CS, Leiferman EM, Frisch KE, et al. The influence of macrophage depletion on ligament healing. Connect Tissue Res 2011;52(3):203-211

34 Kawazoe T, Kim HH. Tissue augmentation by white blood cellcontaining platelet-rich plasma. Cell Transplant 2012;21(2-3): 601-607

35 Chang MY, Chan CK, Braun KR, et al. Monocyte-to-macrophage differentiation: synthesis and secretion of a complex extracellular matrix. J Biol Chem 2012;287(17):14122-14135

36 Gosens T, Peerbooms JC, van Laar W, den Oudsten BL. Ongoing positive effect of platelet-rich plasma versus corticosteroid injection in lateral epicondylitis: a double-blind randomized controlled trial with 2-year follow-up. Am J Sports Med 2011;39(6): 1200-1208

37 Miki A, Rivas-Carrillo JD, Navarro-Alvarez N, et al. Maintenance of neovascularization at the implantation site of an artificial device by bFGF and endothelial cell transplant. Cell Transplant 2006;15 (10):893-901

38 Ono I. The effects of basic fibroblast growth factor (bFGF) on the breaking strength of acute incisional wounds. J Dermatol Sci 2002; 29(2):104-113

39 Spyrou GE, Naylor IL. The effect of basic fibroblast growth factor on scarring. Br J Plast Surg 2002;55(4):275-282

40 Yoshida R, Murray MM. Peripheral blood mononuclear cells enhance the anabolic effects of platelet-rich plasma on anterior cruciate ligament fibroblasts. J Orthop Res 2013;31(1): 29-34

41 Naldini A, Morena E, Fimiani M, Campoccia G, Fossombroni V, Carraro F. The effects of autologous platelet gel on inflammatory cytokine response in human peripheral blood mononuclear cells. Platelets 2008;19(4):268-274

42 Proffen BL, Haslauer CM, Harris CE, Murray MM. Mesenchymal stem cells from the retropatellar fat pad and peripheral blood stimulate ACL fibroblast migration, proliferation, and collagen gene expression. Connect Tissue Res 2013;54(1):14-21

43 Tsay RC, Vo J, Burke A, Eisig SB, Lu HH, Landesberg R. Differential growth factor retention by platelet-rich plasma composites. J Oral Maxillofac Surg 2005;63(4):521-528

44 Sclafani AP, Romo T III, Ukrainsky G, et al. Modulation of wound response and soft tissue ingrowth in synthetic and allogeneic implants with platelet concentrate. Arch Facial Plast Surg 2005; 7(3):163-169

45 Hom DB, Linzie BM, Huang TC. The healing effects of autologous platelet gel on acute human skin wounds. Arch Facial Plast Surg 2007;9(3):174-183

46 Buckley A, Davidson JM, Kamerath CD, Wolt TB, Woodward SC. Sustained release of epidermal growth factor accelerates wound repair. Proc Natl Acad Sci U S A 1985;82(21):7340-7344

47 Anitua E, Sanchez M, Nurden AT, et al. Autologous fibrin matrices: a potential source of biological mediators that modulate tendon cell activities. J Biomed Mater Res A 2006;77(2):285-293

48 Sclafani AP, Saman M. Platelet-rich fibrin matrix for facial plastic surgery. Facial Plast Surg Clin North Am 2012;20(2):177-186, vi

49 Lundquist R, Dziegiel MH, Agren MS. Bioactivity and stability of endogenous fibrogenic factors in platelet-rich fibrin. Wound Repair Regen 2008;16(3):356-363

50 Sclafani AP, McCormick SA. Induction of dermal collagenesis, angiogenesis, and adipogenesis in human skin by injection of platelet-rich fibrin matrix. Arch Facial Plast Surg 2012;14(2): 132-136

51 Sclafani AP. Platelet-rich fibrin matrix for improvement of deep nasolabial folds. J Cosmet Dermatol 2010;9(1):66-71

52 Sclafani AP. Applications of platelet-rich fibrin matrix in facial plastic surgery. Facial Plast Surg 2009;25(4):270-276

53 Sclafani AP. Safety, efficacy, and utility of platelet-rich fibrin matrix in facial plastic surgery. Arch Facial Plast Surg 2011;13(4):247-251

54 Sundaram H, Carruthers J. Volumetric approach to the lower eyelid and midface. Clin Plast Surg 2014; in press

55 Liu B, Earl HM, Baban D, et al. Melanoma cell lines express VEGF receptor KDR and respond to exogenously added VEGF. Biochem Biophys Res Commun 1995;217(3):721-727

56 Zemtsov A, Montalvo-Lugo V. Topically applied growth factors change skin cytoplasmic creatine kinase activity and distribution and produce abnormal keratinocyte differentiation in murine skin. Skin Res Technol 2008;14(3):370-375

57 Graeven U, Fiedler W, Karpinski S, et al. Melanoma-associated expression of vascular endothelial growth factor and its receptors FLT-1 and KDR. J Cancer Res Clin Oncol 1999;125(11):621-629

58 Herold-Mende C, Steiner HH, Andl T, et al. Expression and functional significance of vascular endothelial growth factor receptors in human tumor cells. Lab Invest 1999;79(12):1573-1582

59 Fagien S, Cassuto D. Reconstituted injectable hyaluronic acid: expanded applications in facial aesthetics and additional thoughts on the mechanism of action in cosmetic medicine. Plast Reconstr Surg 2012;130(1):208-217

60 Paliwal S, Fagien S, Sun X, et al. Skin extracellular matrix (ECM) stimulation following injection of a hyaluronic acid-based dermal filler in a rat model. Poster presentation, American Society of Dermatologic Surgery 2013 Annual Meeting. 